\title{
'Small Changes' to Diet and Physical Activity Behaviors for Weight Management
}

\author{
Andrew P. Hills ${ }^{a} \quad$ Nuala M. Byrne ${ }^{b}$ Rachel Lindstrom ${ }^{c} \quad$ James O. Hillc \\ a Mater Mothers' Hospital, Mater Research and Centre for Musculoskeletal Research, Griffith \\ Health Institute, Griffith University, South Brisbane, ${ }^{b}$ Institute of Health and Biomedical \\ Innovation, School of Exercise and Nutrition Sciences, Queensland University of Technology, \\ Brisbane, Australia, 'Anshutz Health and Wellness Center, University of Colorado School of \\ Medicine, Aurora, CO, USA
}

\section{Key Words}

Small changes · Diet $\cdot$ Activity $\cdot$ Behaviors $\cdot$ Weight management

\begin{abstract}
Obesity is associated with numerous short- and long-term health consequences. Low levels of physical activity and poor dietary habits are consistent with an increased risk of obesity in an obesogenic environment. Relatively little research has investigated associations between eating and activity behaviors by using a systems biology approach and by considering the dynamics of the energy balance concept. A significant body of research indicates that a small positive energy balance over time is sufficient to cause weight gain in many individuals. In contrast, small changes in nutrition and physical activity behaviors can prevent weight gain. In the context of weight management, it may be more feasible for most people to make small compared to large short-term changes in diet and activity. This paper presents a case for the use of small and incremental changes in diet and physical activity for improved weight management in the context of a toxic obesogenic environment.
\end{abstract}

Copyright $\odot 2013$ S. Karger GmbH, Freiburg

\section{Introduction}

Approximately $25 \%$ of children in the developed world are overweight or obese [1] and prevalence rates in the developing world are alarming [2]. Consistent with the many shortand long-term physiological and psychological health consequences, obesity in childhood and adolescence has been described as one of the most important global health problems of our 
Hills et al.: 'Small Changes' to Diet and Physical Activity Behaviors for Weight Management

time $[1,3,4]$. The prevalence of overweight and obesity is also high in adults and ranges from 40-60\% in most developed countries [5].

At any age, low levels of physical activity and poor dietary habits are consistent with an increased risk of overweight and obesity as well as related comorbidities. Diet and physical activity are two of the most modifiable risk factors for overweight and obesity, however, relatively little research has investigated the associations between these complex behaviors in light of other environmental drivers [6, 7]. For effective weight management, one needs to understand the dynamics of the energy balance equation and the wider environmental context.

Recent data suggests that overweight and obesity constitute $5 \%$ of global mortality. Physical inactivity represents another great public health challenge and is responsible for $6 \%$ of deaths globally $[8,9]$. In the USA, an estimated $42 \%$ of 6 - to 11 -year-old children and only $8 \%$ of 12 - to 17-year-olds meet daily physical activity recommendations [10]. Colley et al. [11] recently reported that physical activity levels of Canadian children and youth are similarly very low. In Australia, young people engage in significantly lower levels of moderate- to vigorous-intensity physical activity than recommended $[12,13]$. Increased energy intake is associated with a range of factors [6], including a higher intake of energy-dense foods [14], food and drink low in nutritive value, and lower intakes of fruit, vegetables, and fiber $[15,16]$.

In 2003, Hill et al. [17] suggested that small behavior changes could be sufficient to prevent excess population weight gain. They hypothesized that small changes are more likely to be feasible and sustainable and that a change in energy balance of only 100 kcal per day may be sufficient to prevent population weight gain. This is consistent with studies in adults that a small positive energy balance over time is sufficient to cause weight gain [18]. Similarly for growing children, the mismatch between energy requirements for growth and positive energy balance resulting in excess weight gain (energy gap) has been calculated as 100-200 kcal per day $[19,20]$. The primary purpose of this paper is to address the benefits of small and incremental changes in diet and activity behaviors in the context of weight management, however, we acknowledge that the biological control of energy balance is complex and influenced by a host of envirogenomic factors.

\section{A 'Small-Changes' Approach}

If indeed most individuals are more responsive to approaches to encourage small changes to improve health behaviors, this would inform the public health promotion of nutrition and physical activity. In the context of weight management, this could result in the translation of knowledge to improve the design of interventions for the benefit of mothers, their children, and the wider family.

The paper by Hill et al. [17] published in Science and a later publication [21] suggested that there was an urgent need to push back against the many environmental factors responsible for the gradual weight gain of the population. Rather than focus on weight loss per se, or the prevention of obesity, Hill et al. [17] suggested that initial efforts should focus on promoting small lifestyle changes to eliminate or reduce 'incremental weight gain'. This was not the first attempt to promote small behavior changes, however, in the context of obesity, Hill [21] contended the following:

- Compared to large changes, small changes are more realistic, feasible to achieve and maintain. Consistent with the literature, a daily caloric deficit of $200 \mathrm{kcal}$ or less may have the advantage of minimizing the decrease in metabolic rate typically associated with weight loss and also not increase hunger [22]. Increasing energy expenditure by $100 \mathrm{kcal}$ over the course of a day is also not associated with feelings of fatigue or increased drive to eat [23]. 
- Small changes in diet and/or physical activity, despite being less than the public health recommendations, may be sufficient to prevent gradual weight gain.

- If self-efficacy is enhanced as a function of achieving small lifestyle changes, this may foster additional changes and ultimately lead to larger changes. (We recognize that selfefficacy may also be enhanced through rapid short-term weight loss but weight lost using this approach is typically regained over time.)

- The 'small-changes' approach could be used to help reduce environmental forces that promote increases in energy intake and decreases in physical activity.

The argument for a 'small-changes' approach is also based on the observation that many individuals gain weight gradually over an extended period, the so-called creeping obesity. Small daily discrepancies in energy balance (the 'energy gap') could be countered by small increases in energy expenditure or decreases in energy intake by $100 \mathrm{kcal}$ per day. Detailed information regarding the 'energy gap' concept can be found in a number of papers [21, 24, 25].

Since 2003, the 'small-changes' approach has gained considerable traction in numerous government and non-government initiatives. The 'small-changes' initiative of the US Department of Health and Human Services' included television and radio commercials and a website (www.smallstep.gov). The approach was also promoted by the US Surgeon General (www.surgeongeneral.gov/initiatives/prevention/index.html), and recommended by the American Diabetes and Heart Associations as well as American Cancer Society.

America On the Move (AOM) (www.americaonthemove.org) was formed to promote the 'small-changes' approach to prevent weight gain and improve health. The starting goal is to increase activity level by 2,000 steps per day and decrease energy intake by $100 \mathrm{kcal}$ per day. The use of this approach in the Colorado On The Move program resulted in significant increases in daily walking [26].

The efficacy of AOM in the prevention of weight gain was tested in two family-based interventions $[27,28]$. In the first, families were asked to make two small changes to daily routines, i.e. consume cereal for breakfast and increase physical activity by 2,000 steps per day [27]. There was a significantly lower increase in BMI-for-age for intervention versus control children over 14 weeks and intervention group mothers also reduced their BMI level.

In the second intervention [28], energy intake was reduced by $100 \mathrm{kcal}$ per day by replacing sugar and sugar-containing beverages with artificial sweeteners or products containing artificial sweeteners (but no calories). Intervention families were also asked to increase daily steps by 2,000 (over the baseline number). Significantly more children in the intervention group maintained or decreased BMI-for-age across the 6-month intervention.

Stroebele et al. [29] evaluated the short-term effectiveness and usefulness of the AOM message by providing 100 simple tips to decrease food intake by $100 \mathrm{kcal}$ per day. Energy intake was reduced more at the meals where tips were used which underlined the feasibility and ease of understanding of the 'small-changes' approach. However, major limitations of the study were the small sample and short duration.

Evidence for small changes in relation to weight loss stems from the ASPIRE trial [30] in which overweight and obese sedentary adults randomized to a 16-week intervention lost significantly more weight than both the standard didactic or control group. Despite the modest weight loss (average of $4.62 \mathrm{~kg}$ ) in the 'small-changes' group, it was clinically significant ( $5 \%$ of body weight). The 'small-changes' group also maintained weight loss, decreased waist circumference, and abdominal fat loss at 3 months post-intervention. Similar results were also reported in a 12-week 'small-changes' telephonic intervention in sedentary obese veterans [31]. Findings from other community-based studies [32] support the benefits of small diet- and physical activity-related lifestyle change and a healthy body weight. 
Most food industry interest in the 'small-changes' approach has related to portion size and the increased popularity of 100 -kcal snacks, however, more research is needed in this area [21]. Lloyd-Williams et al. [33] examined the potential public health impact on coronary heart disease and stroke mortality of replacing one 'unhealthy' snack with one 'healthy' snack per person, per day across the UK population. They reported that small changes to diet (such as choosing healthy snacks) could lead to potentially large reductions in cardiovascular deaths. Readers are referred to a number of reviews in relation to physical activity interventions designed to increase the number of steps per day [34,35]. Typically, pedometers have been used to motivate and also quantify steps per day.

In the school setting, the Take 10 Program is a 'small-changes' approach designed to increase activity energy expenditure across the academic curriculum rather than rely on physical education and sport for extra energy expenditure (www.take10.net). A recent schoolbased intervention using pedometers and e-mail support was successful in promoting physical activity and selected healthy eating behaviors in adolescent boys and girls [36].

Despite lengthy periods of inactivity, many individuals make unrealistic and/or large changes in energy expenditure on commencement of an activity program. The risks of such an approach include soreness, discomfort, injury, and reduced motivation to exercise. Large increases in physical activity energy expenditure may not be accompanied by a concomitant negative daily energy balance $[37,38]$, primarily due to an increase in energy intake. A parallel from a dietary perspective is the inability to sustain a significant restriction in energy intake, particularly when food is unpalatable.

Given the extent of global overweight and obesity, it has been postulated that sweeping changes in policy, food supply, and environment are needed to arrest and reverse the epidemic [39]. The 'small-changes' approach is not at odds with such claims nor is it seen as the panacea for the obesity problem. Rather, the 'small-changes' approach is one of many needed in a multi-disciplinary, multi-sectoral approach to the prevention and management of obesity. Nader et al. [40] suggested that approaches begin as early as possible and use a systems framework to both implement health behavior and environmental changes in communities.

\section{Diet and Physical Activity Interventions for Behavior Change}

The majority of interventions to assist individuals in changing eating and activity behaviors have had limited effects [41, 42]. In the recent past, a major public health emphasis has been on social-ecological models with multiple influences on individual (biological, psychological), social and cultural, organizational (schools, workplaces), and community (including physical activity and food environments) behaviors [43]. A useful synthesis of environmental correlates of physical activity and dietary behavior in young people is provided in a systematic review of reviews by de Vet et al. [44].

Eating and activity choices are influenced by a complex, interrelated set of 'determinants' [45] including different cognitions plus environmental factors such as food availability and accessibility [46]. Successful behavior change approaches are associated with the ability to identify and influence these determinants.

Brug et al. [45] have argued that greater understanding is required of the integration of potential determinants of diet and activity behaviors at both individual and environmental levels [47], rather than highlighting the importance of individual, social, or physical environmental factors in shaping nutrition and physical activity behaviors. This would facilitate the study of the relative importance of motivation, abilities, and opportunities as determinants of nutrition and physical activity behaviors [48]. 
As diet and activity behaviors, particularly those associated with weight gain, are not easy to change, a move beyond an 'individual versus environment' debate to the integrative approach proposed by Brug et al. [45] is needed. Improvements in the environment may assist people to make healthy diet and activity choices; however, personal choice is only as good as the options available [49].

In summary, diet and physical activity interventions to build knowledge, motivation, and behavior change skills in individuals are more likely to be effective if the environment also changes. A 'small-changes' approach appears logical within this contextual framework.

\section{Transtheoretical Model and Stages of Change Concept}

One of the most commonly adopted theoretical frameworks [50] for nutrition [51] and physical activity [52] behavior change interventions is the multi-dimensional transtheoretical model (TTM) [53,54]. More commonly, reference is made to the stages of change (a classification of behavior change into five distinct stages) rather than the full TTM [50].

The five stages of individual behavior change are: (1) Precontemplation: the individual has no intention to change problematic diet and activity behavior(s); (2) Contemplation: the individual intends to change his or her behavior within the next 6 months; (3) Preparation: during which the individual tries the new behavior and intends to change it within the next month; (4) Action: in which an individual has adopted a new behavior less than 6 months ago, and finally, (5) Maintenance: the individual has successfully changed and maintained from a poor behavior for more than 6 months.

Prochaska et al. [54] also reported on ten strategies or 'processes of change' which individuals use while passing through successive stages. A key component of behavior change (and the TTM) is self-efficacy, i.e. one's belief in their ability to effect change. With improved self-efficacy the perceived advantages of behavior change increase, while at the same time perceived disadvantages decrease. Behavior change is cyclical and involves both progress and periodic relapse so that some individuals, even with successful behavior change, may move back and forth between the five stages before actioning and, eventually, maintaining the change(s). Earlier work by Sallis and Nader [55] suggested a stage approach to explain movement behavior in family groups and were interested in better understanding the cyclical patterns of participation in physical activity, including adoption, maintenance, and relapse. This staged approach sits comfortably with the 'small-changes' approach to nutrition and activity behaviors, including family, school, and community settings.

Understanding an individual's stage of change may be useful in providing appropriate advice and support around diet and activity behaviors, also in relation to weight management. For maximum benefit, in addition to the assessment of stage based on an individual's selfperception of diet and activity, there should be an objective assessment of diet and activity to serve as a starting point to increase the individual's knowledge and understanding in this area. An appreciation of stage of change in relation to diet and activity behaviors may also assist the educator, health professional, or parent to provide motivation and information at strategic times to facilitate and potentially accelerate behavior change.

Most important in the context of behavior change is the action phase or what will ensure an individual 'actions' a change to their diet and physical activity. The most important task of the parent, older sibling, or health professional is to ensure that an individual's motivation to change is high by positively rewarding the smallest of changes [56] and setting realistic and achievable goals. The stage of change approach is popular and widely accepted because it is brief, has high face validity, and is easy to understand $[57,58]$. However, criticism of the approach relates to much of the evidence being generated from cross-sectional studies [57, 59]. 
A range of approaches has been suggested to improve the translation of one's intention to perform/change a particular behavior and to bridge the intention-behavior gap including goal-setting [60], self-monitoring, and skills training [61] plus self-efficacy [62]. More recent emphasis has been placed on environmental changes to increase opportunities for healthy nutrition and physical activity behaviors and/or to reduce the opportunities for unhealthy behaviors [45]. Such emphases are logical parallels to the 'small-changes' approach in an obesogenic environment $[63,64]$.

\section{Parental Support and Diet and Activity Behavior of Children}

Dietary behavior of children is determined by individual factors such as food preferences, socio-cultural factors including peer norms, and parent attitudes/beliefs, plus environmental factors such as availability of healthy food $[65,66]$. A number of maternal and family characteristics are strongly associated with diet quality in pre-school age children [67] and potentially influence eating behavior through adolescence and into adulthood. Parents are pivotal influences on a child's diet [66] and largely govern the ability and opportunity of the child to make healthy or unhealthy dietary choices $[68,69]$. The degree to which parents provide a healthy environment, along with their role modeling, particularly in relation to size, shape, and body weight, and nutritional knowledge are important [71-74]. An overview of the range of parental practices associated with child eating, physical activity behaviors, and weight status is provided in a review by Skouteris et al. [70].

Parental modeling of activity behavior may also be central to the promotion of physical activity among children, particularly younger children; however, most studies to date have been based on self-report [75-78]. More work is needed to identify the most effective parental strategies to enable children to be as active as possible.

In short, parents and other caregivers have a primary influence on the diet [66] and on activity-related behavior patterns of children and adolescents [79-81]. Parents serve as role models, reinforcers, and advocates of both health-enhancing and health-compromising behaviors [82] of young people. Parents have also been described as gatekeepers to both diet and physical activity education and opportunities [83] as demonstrated in the longer-term effects on adult activity-related behavior patterns [84]. As such, parents of primary schoolaged children are in an extremely powerful position to support and influence positive behaviors.

In summary, parents influence children's activity behaviors in a range of ways [85], including the parents' own activity levels [86], attitudes, beliefs, and values toward physical activity [87], and social support [88, 89]; however, the most effective method to engage parents is unclear. A recent review by Hingle et al. [66] concluded that there are insufficient studies to determine whether parental involvement enhanced the effectiveness of dietary interventions. However, 'direct' strategies for involving parents were more effective than 'indirect' (except when children were responsible for engaging their parents). Engaging parents and children in 'small-changes' approaches to improve health behaviors appears to be a sensible goal.

\section{The Energy Balance Equation and Implications for Approaches to Modify Diet and Physical Activity}

Despite a widespread appreciation of the energy balance equation - matching energy intake with energy expenditure for weight maintenance - restrictions in energy intake and increases in energy expenditure necessary for weight maintenance, or weight loss, are 
Hills et al.: 'Small Changes' to Diet and Physical Activity Behaviors for Weight Management

commonly not sustained in the overweight and obese. A poor response to informal and structured weight management approaches [90] is associated with a failure to adopt and/or persist with the necessary health behaviors.

Ekkikakis [8] has purported that attempts to understand the behavioral mechanisms underlying the processes of engaging in, adhering to, and disengaging from physical activity have not been particularly successful. This may be one of the reasons for the relatively modest results of interventions designed to increase public participation and adherence in diet and physical activity [91].

An additional poorly understood factor is the motivational significance of the physical activity stimulus itself [8], i.e., the willingness or desire of people to repeat this behavior based on subjective experiences. When an activity (or a food) is enjoyed one is more likely to repeat that behavior. Increasingly, the literature has referenced hedonics with respect to appetite and dietary intake [92] but this may also apply to the motivation to exercise [93]. Exercise may also influence eating behavior by modulating the hedonic response to foods [92]. The contrary position is that if an activity is uncomfortable, causes pain or distress, the likelihood of repeating or adhering to the activity may be reduced. The association between affect and physical activity behavior is well supported in the literature [94, 95]. Similarly, unattractive and significantly restricted diets are not appealing or sustainable.

The preference of many adults for autonomously performed activity may relate to the self-determination theory and the suggestion that perceived autonomy is a basic psychological need [96]. Unfortunately, we have engineered physical activity out of the daily lives of children and also often impose adult restrictions on activity time and movement opportunities. The same is true for restrictions in the range of healthy food and drink children are exposed to in the home and school settings.

Maintenance of a sense of perceived autonomy is more likely to be experienced as pleasant and self-rewarding which is conducive to intrinsic motivation. In contrast, where perceived autonomy is lost it is more likely to be experienced as unpleasant as when an externally imposed exercise prescription includes an exercise intensity unsuited to the individual or uninformed adults dictate the activity practices of children. In adults, the ability to select one's preferred mode of exercise is also associated with improved affective responses [9799].

Positive changes in diet and activity are also likely to maximise behavioral maintenance because the changes are intrinsically pleasant and rewarding. This is not a new phenomenon as many years ago Pollock et al. [100] identified the importance of individualized prescriptions of physical activity to maximize both physiological effectiveness and enjoyment or tolerability. For individuals of all ages, exercise and physical activity should satisfy health and fitness goals and also be enjoyable and rewarding. Small lifestyle changes can make a difference, particularly in a context where the multiple factors contributing to obesity such as energy-dense diets, sedentary lifestyles, and weight-sustaining behaviors are addressed.

Physical activity is often considered less important than food intake in weight management despite regular physical activity being the strongest predictor of weight maintenance. There is strong evidence that lifestyle approaches for weight management should include physical activity, dietary change, and behavioral components [101, 102]. Improvements in self-efficacy associated with physical activity will also have parallel benefits for diet through healthier eating behaviors [103]. Psychological considerations such as affect, enjoyment, perceived autonomy, control, and competence should be much more prominent in the public health promotion of physical activity and the prescription of exercise at the individual level. 
Hills et al.: 'Small Changes' to Diet and Physical Activity Behaviors for Weight Management

\section{Conclusion}

Research has highlighted the merits of a 'small-changes' approach to increase physical activity, prevent weight gain, and improve nutrition and physical activity behaviors; however, the concept is relatively new. To date, numerous school-, community-, and population-based initiatives have successfully implemented the approach; however, further work is required to test its efficacy and effectiveness. Many individuals, particularly the overweight and obese, may be more responsive to approaches to encourage small changes for improving diet and activity behaviors. The approach has considerable merit, however, the real test will be its ability to contribute to sustained behavior change for weight management.

\section{Disclosure Statement}

The authors have no conflicts of interest to declare.

\section{References}

1 Lobstein T, Baur LA, Uauy R: Obesity in children and young people. Obes Rev 2004;5:4-85.

2 Wang Y, Lobstein T: Worldwide trends in childhood overweight and obesity. Int J Pediatr Obes 2006;1:11-25.

3 Haslam DW, James WPT: Obesity. Lancet 2005;366:1197-1209.

-4 Hills AP, Okely AD, Baur LA: Addressing childhood obesity through increased physical activity. Nat Rev Endocrinol 2010;6:543-549.

5 Hill JO, Peters JC, Catenacci VA, Wyatt HR: International strategies to address obesity. Obes Rev 2008;9 (suppl 1):41-47.

6 Giskes K, van Lenthe F, Avendano-Pabon M, Brug J: A systematic review of environmental factors and obesogenic dietary intakes among adults: are we getting closer to understanding obesogenic environments? Obes Rev 2011;12:e95-e106.

7 Corder K, van Sluijs EMF, Steele RM, Stephen AM, Dunn V, Bamber D, et al: Breakfast consumption and physical activity in British adolescents. Br J Nutr 2010;1:1-6.

$>8$ Ekkikakis P: Let them roam free? Physiological and psychological evidence for the potential of self-selected exercise intensity in public health. Sports Med 2009;39:857-888.

9 WHO: Global Recommendations for Physical Activity and Health. Geneva, World Health Organisation, 2010.

10 Troiano RP, Berrigan D, Dodd KW, Masse LC, Tilert T, McDowell M: Physical activity in the United States measured by accelerometer. Med Sci Sports Exerc 2008;40:181-188.

-11 Colley RC, Garriguet D, Janssen I, Craig CL, Clarke J, Tremblay MS: Physical activity of Canadian children and youth: accelerometer results from the 2007 to 2009 Canadian Health Measures Survey. Health Rep 2011;22: $1-9$.

12 Cleland V, Crawford D, Baur LA, Hume C, Timperio A, Salmon J: A prospective examination of children's time spent outdoors, objectively measured physical activity and overweight. Int J Obes (London) 2008;32:16851693.

13 Ball K, Cleland VJ, Timperio AF, Salmon J, Crawford DA: Socioeconomic position and children's physical activity and sedentary behaviours: longitudinal findings from the CLAN study. J Phys Act Health 2009;6:289-298.

14 Bauer KW, Larson NI, Nelson MC, Story M, Neumark-Sztainer D: Fast food intake among adolescents: secular and longitudinal trends from 1999 to 2004. Prev Med 2009;48:284-287.

15 Branca F, Nikogosian H, Lobstein T: Dietary Determinants of Obesity. The Challenge of Obesity in the WHO European Region and the Strategies for Response. WHO Regional Office for Europe, Copenhagen, 2007, pp 46-54.

16 Larson NI, Neumark-Sztainer D, Hannan PJ, Story M: Trends in adolescent fruit and vegetable consumption, 1999-2004. Project EAT. Am J Prev Med 2007;32:147-150.

$\checkmark 17$ Hill JO, Wyatt HR, Reed GW, Peters JC: Obesity and the environment: Where do we go from here? Science 2003; 299:853-855.

18 Brown WJ, Williams L, Ford JH, Ball K, Dobson AJ: Identifying the energy gap: magnitude and determinants of 5-year weight gain in mid-age women. Obes Res 2005; 13:1431-1441.

19 Wang YC, Gortmaker SL, Sobol AM, Kuntz KM: Estimating the energy gap among US children: a counterfactual approach. Pediatrics 2006;118:e1721-e1733.

20 Plachta-Danielzik S, Landsberg B, Bosy-Westphal A, Johannsen M, Lange D, Muller M: Energy gain and energy gap in normal-weight children: longitudinal data of the KOPS. Obesity (Silver Spring) 2008;16:777-783. 


\begin{tabular}{l|l}
\hline \multicolumn{2}{l}{ Obes Facts 2013;6:228-238 } \\
\hline DOI: $10.1159 / 000345030$ & $\begin{array}{l}\text { C) 2013 S. Karger GmbH, Freiburg } \\
\text { www.karger.com/ofa }\end{array}$ \\
\hline
\end{tabular}

Hills et al.: 'Small Changes' to Diet and Physical Activity Behaviors for Weight Management

21 Hill JO: Can a small-changes approach help address the obesity epidemic? A report of the Joint Task Force of the American Society for Nutrition, Institute of Food Technologists and International Food Information Council. Am J Clin Nutr 2009;89:477-484.

$\checkmark 22$ Rolls BJ, Morris EL, Roe LS: Portion size of food affects energy intake in normal-weight and overweight men and women. Am J Clin Nutr 2002;76:1207-1213.

23 Koulouri AA, Tigbe WW, Lean ME: The effect of advice to walk 2000 extra steps daily on food intake. J Hum Nutr Diet 2006;19:263-266.

24 Swinburn BA, Sacks G, Ravussin E: Increased food energy supply is more than sufficient to explain the US epidemic of obesity. Am J Clin Nutr 2009;90:1453-1456.

25 Swinburn BA, Sacks G, Lo SK, Westerterp KR, Rush EC, Rosenbaum M, et al: Estimating the changes in energy flux that characterize the rise in obesity prevalence. Am J Clin Nutr 2009;89:1723-1728.

26 Wyatt HR, Peters JC, Reed GW, Grunwald GK, Barry M, Thompson H, et al: Using electronic step counters to increase lifestyle physical activity: Colorado on the Move. J Phys Act Health 2004;1:181-191.

-27 Rodearmel SJ, Wyatt HR, Barry MJ, Dong F, Pan D, Israel RG, et al: A family-based approach to preventing excessive weight gain. Obesity (Silver Spring) 2006;14:1392-1401.

28 Rodearmel SJ, Wyatt HR, Stroebele N, Smith S, Ogden L, Hill JO: Small changes in dietary sugar and physical activity as an approach to preventing excessive weight gain: the America on the Move Family Study. Pediatrics 2007;120:869-879.

29 Stroebele N, de Castro JM, Stuht J, Catenacci V, Wyatt HR, Hill JO: A small-changes approach reduces energy intake in free-living humans. J Am Coll Nutr 2009;28:63-68.

- 30 Lutes LD, Winett RA, Barger SD, Wojcik JR, Herbert WG, Nickols-Richardson SM, et al: Small changes in nutrition and physical activity promote weight loss and maintenance: 3-month evidence from the ASPIRE randomized trial. Ann Behav Med 2008;35:351-357.

-31 Damschroder LJ, Lutes LD, Goodrich DE, Gillon L, Lowery JC: A small-change approach delivered via telephone promotes weight loss in veterans: Results from the ASPIRE-VA pilot study. Patient Educ Couns 2010;79:262266.

-32 Hill JO, Thompson H, Wyatt H: Weight maintenance: what's missing? J Am Diet Assoc 2005; 105:S63-S66.

33 Lloyd-Williams F, Mwatsama M, Ireland R, Capewell S: Small changes in snacking behaviour: the potential impact on CVD mortality. Public Health Nutr 2009;12:871-876.

-34 Ogilvie D, Foster CE, Rothnie H, Cavill N, Hamilton V, Fitzsimons CF, et al: Scottish Physical Activity Research Collaboration. Interventions to promote walking: systematic review. BMJ 2007;334:1204-1213.

-35 Bravata DM, Smith-Spangler C, Sundaram V, Gienger AL, Lin N, Lewis R, et al: Using pedometers to increase physical activity and improve health. JAMA 2007;298:2296-2304.

-36 Lubans DR, Morgan PJ, Callister R, Collins CE: Effects of integrating pedometers, parental materials, and E-mail support within an extracurricular school sport intervention. J Adolesc Health 2009;44:176-83.

-37 Martins C, Kulseng B, King NA, Holst JJ, Blundell JE: The effects of exercise-induced weight loss on appetiterelated peptides and motivation to eat. J Clin Endocrinol Metab 2010;95:1609-1616.

-38 Stubbs RJ, Sepp A, Hughes DA, Johnstone AM, King N, Horgan G, et al: The effect of graded levels of exercise on energy intake and balance in free-living women. Int J Obes Relat Metab Disord 2002;26:866-869.

-39 Rigby NJ, Muller MJ: A small step for obesity but a great leap in the wrong direction for mankind. Obes Facts 2009;2:63-65.

40 Nader PR, Huang TT, Gahagan S, Kumanyika S, Hammond RA, Christoffel KK: Next steps in obesity prevention: altering early life systems to support healthy parents, infants and toddlers. Child Obes 2012;8:195-204.

-41 Kumanyika SK, Van Horn L, Bowen D, Perri MG, Rolls BJ, Czajkowski SM, et al: Maintenance of dietary behaviour change. Health Psychol 2000;19:42-56.

42 Marcus BH, Dubbert PM, Forsyth LH, McKenzie TL, Stone EJ, Dunn AL, et al: Physical activity behaviour change: issues in adoption and maintenance. Health Psychol 2000;19:32-41.

43 Sallis JF, Glanz K: Physical activity and food environments: solutions to the obesity epidemic. Milbank Q 2009; 87:123-154.

$\$ 44$ de Vet E, de Ridder DTD, de Wit JBF: Environmental correlates of physical activity and dietary behaviours among young people: a systematic review of reviews. Obes Rev 2011;15:e130-e142.

45 Brug J, Oenema A, Ferreira I: Theory, evidence and Intervention Mapping to improve behaviour nutrition and physical activity interventions. Int J Behav Nutr Phys Act 2005;2:2.

-46 Baranowski TC, Anderson CC: Mediating variable framework in physical activity interventions: How are we doing? How might we do better? Am J Prev Med 1998;15:266-297.

47 Kok G, Schaalma H, Ruiter R, Empelen P van, Brug J: Intervention mapping: a protocol for applying health psychology theory to prevention programmes. J Health Psychol 2004;9:85-89.

-48 Ball K, Crawford D: The obesity epidemic: contextual influences on physical activity and body weight. J Sci Med Sport 2003;6:377-378.

49 Adler NE, Stewart J: Reducing obesity: motivating action while not blaming the victim. Milbank Q 2009;87: 49-70.

50 Hutchison AJ, Breckon JD, Johnston LH: Physical activity behaviour change interventions based on the Transtheoretical Model: a systematic review. Health Educ Behav 2009;36:829-845.

51 Steptoe A, Wijetunge S, Doherty S, Wardle J: Stages of change for fat reduction: associations with food intake, decisional balance and motives for food choice. Health Educ J 1996;55:108-122. 
Hills et al.: 'Small Changes' to Diet and Physical Activity Behaviors for Weight Management

52 Kim C, Hwang A, Yoo J: The impact of a stage matched intervention to promote exercise behaviour in participants with type 2 diabetes. Int J Nurs Stud 2004;41:833-841.

53 Prochaska JO, DiClemente CC: Stages and processes of self-change of smoking: toward an integrative model of change. J Consult Clin Psychol 1983;51:390-395.

54 Prochaska JO, DiClemente CC, Norcross JC: In search of how people change: applications to addictive behaviours. Am Psychol 1992;47:1102-1114.

55 Sallis JF, Nader P: Family determinants of health behaviors; in Gochman D (ed): Health Behavior: Emerging Research Perspectives. New York, Plenum, 1988, pp 107-124.

56 Koster FRT, Verheijden MW, Baartmans JA: The power of communication. Modifying behaviour: effectively influencing nutrition patterns of patients. Eur J Clin Nutr 2005;59:S17-S22.

57 Adams JWM: Why don't stage-based activity promotion interventions work? Health Educ Res 2004;20:237243.

58 van Sluijs EM, van Poppel MN, van Mechelen W: Stage-based lifestyle interventions in primary care: are they effective? Am J Prev Med 2004;26:330-343.

59 Sutton S: Interpreting cross-sectional data on stages of change. Psychol Health 2000;15:163-171.

60 Schwarzer R, Renner B: Social-cognitive predictors of health behavior: action self-efficacy and coping selfefficacy. Health Psychol 2000;19:487-495.

61 Baranowski T, Cullen KW, Nicklas T, Thompson D, Baranowski J: Are current health behavioural change models helpful in guiding prevention of weight gain efforts? Obes Res 2003;11:23S-43S.

62 Prestwich A, Lawton R, Connor M: The use of implementation intentions and the decision balance sheet in promoting exercise behaviour. Psychol Health 2003;18:707-721.

63 Schwartz MB, Puhl R: Childhood obesity: a societal problem to solve. Obes Rev 2003;4:57-71.

64 Swinburn BA, Caterson I, Seidell JC, James WP: Diet, nutrition and the prevention of excess weight gain and obesity. Public Health Nutr 2004;7:123-146.

65 French S, Story M, Jeffery R: Environmental influences on eating and physical activity. Ann Rev Public Health 2001;22:309-335.

-66 Hingle MD, O'Connor TM, Dave JM, Baranowski T: Parental involvement in interventions to improve child dietary intake: a systematic review. Prev Med 2010;51:103-111.

67 Fisk CM, Crozier SR, Inskip HM, Godfrey KM, Cooper C, Robinson SM; The Southampton Women's Survey Study Group: Influences on the quality of young children's diets: the importance of maternal food choices. Br J Nutr 2010;1:1-9.

-68 Hoerr S, Hughes SO, Fisher JO, Nicklas TA, Liu Y, Shewchuk RM: Associations among parental feeding styles and children's food intake in families with limited incomes. Int J Behav Nutr Phys Act 2009;6:55.

69 Rennie KL, Johnson L, Jebb SA: Behavioural determinants of obesity. Best Pract Res Clin Endocrinol Metab 2005; 19:343-358.

70 Skouteris H, McCabe M, Swinburn B, Newgreen V, Sacher P, Chadwick P: Parental influence and obesity prevention in preschoolers: a systematic review of interventions. Obes Rev 2010;12:315-328.

71 Faith MS, Scanlon KS, Birch LL, Francis LA, Sherry B: Parent-child feeding strategies and their relationships to child eating and weight status. Obes Res 2004;12:1711-1722.

72 Faith MS, Kerns J: Infant and child feeding practices and childhood overweight: the role of restriction. Matern Child Nutr 2005;1:164-168.

73 Farrow C, Blissett J: Controlling feeding practices: cause or consequence of early child weight? Pediatrics 2008;121:164-169.

74 Pugliese J, Tinsley B: Parental socialization of child and adolescent physical activity: a meta-analysis. J Fam Psychol 2007;21:331-343.

75 Gustafson SL, Rhodes RE: Parental correlates of physical activity in children and early adolescents. Sports Med 2006;36:79-97.

76 Davison KK, Cutting TM, Birch LL: Parents' activity-related parenting practices predict girls' physical activity. Med Sci Sports Exerc 2003;35:1589-1595.

77 Jago R, Thompson JL, Page AS, Brockman R, Cartwright K, Fox KR: Licence to be active: parental concerns and 10-11-year-old children's ability to be independently physically active. J Public Health (Oxf) 2009;31:472477.

-78 Jago R, Fox KR, Page AS, Brockman R, Thompson JL: Parent and child physical activity and sedentary time: do active parents foster active children? BMC Public Health 2010;10:194.

79 Kohl HW, Hobbs F: Development of physical activity behaviours among children and adolescents. Pediatrics 1998;101:549-554.

80 Lindsay AC, Sussner KM, Kim J, Gortmaker S: The role of parents in preventing childhood obesity. Future Child 2006;16:169-186.

81 Sallis JF, Prochaska JJ, Taylor WC: A review of correlates of physical activity of children and adolescents. Med Sci Sports Exerc 2000;32:963-975.

82 Schor EL: American Academy of Pediatrics Task Force on the Family. Family pediatrics: Report of the Task Force on the Family. Pediatrics 2003;111:1541-1571.

-83 Hopper CA, Gruber MB, Munoz KD, Herb RA: Effect of including parents in a school-based exercise and nutrition program for children. Res Q Exerc Sport 1992;63:315-321. 
Hills et al.: 'Small Changes' to Diet and Physical Activity Behaviors for Weight Management

84 Thompson AM, Humbert ML, Mirwald RL: A longitudinal study of the impact of childhood and adolescent physical activity experiences on adult physical activity perceptions and behaviours. Qual Health Res 2003;13: 358-377.

85 Taylor WC, Baranowski T, Sallis JF: Family determinants of childhood physical activity: a social-cognitive model; in Dishman RK (ed): Advances in Exercise Adherence. Champaign, IL, Human Kinetics, 1994, pp 319-342.

86 Raudsepp L, Viira R: Influence of parents' and siblings' physical activity on activity levels of adolescents. Eur J Phys Educ 2000;5:169-178.

87 Kimiecik JC, Horn TS, Shurin CS: Relationships among children's beliefs, perceptions of their parents' beliefs, and their moderate-to-vigorous physical activity. Res Q Exerc Sport 1996;67:324-336.

88 Sallis JF, Alcaraz JE, McKenzie TL, Hovell MF: Predictors of change in children's physical activity over 20 months. Am J Prev Med 1999;16:222-229.

89 Trost SG, Sallis JF, Pate RR, Freedson PS, Taylor WC, Dowda M: Evaluating a model of parental influence on youth physical activity. Am J Prev Med 2003;25:277-282.

90 Mann T, Tomiyama J, Westling E, Lew AM, Samuels B, Chatman J: Medicare's search for effective obesity treatments: diets are not the answer. Am Psychol 2007;62:220-233.

91 Dishman RK, Buckworth J: Increasing physical activity: a quantitative synthesis. Med Sci Sports Exerc 1996; 28:706-719.

92 King NA, Cauldwell P, Hopkins M, Byrne NM, Colley R, Hills AP, et al: Metabolic and behavioural compensatory responses to exercise interventions: barriers to weight loss. Obesity (Silver Spring) 2007;15:1373-1383.

93 Kahneman D: Objective happiness; in Kahneman D, Diener E, Schwarz N (eds): Well-Being: The Foundation of Hedonic Psychology. New York, Russell Sage Foundation, 1999, pp 3-25.

94 Kiviniemi MT, Voss-HumkeAM, Seifert AL: How do I feel about the behavior? The interplay of affective associations with behaviors and cognitive beliefs as influences on physical activity behavior. Health Psychol 2007; 26:152-158.

95 Williams DM, Dunsiger S, Ciccolo JT, Lewis BA, Albrecht AE, Marcus BH: Acute affective response to a moderateintensity exercise stimulus predicts physical activity participation 6 and 12 months later. Psychol Sport Exerc 2008;9:231-245.

96 Deci EL, Ryan RM: The 'what' and 'why' of goal pursuits: human needs and the self-determination of behaviour. Psychol Inq 2000;11:227-268.

97 Daley AJ, Meynard IW: Preferred exercise mode and affective responses in physically active adults. Psychol Sport Exerc 2003;4:347-356.

98 Miller BM, Bartholomew JB, Springer BA: Post-exercise affect: the effect of mode preference. J Appl Sport Psychol 2005; 17:263-272.

99 Parfitt G, Gledhill C: The effect of choice of exercise mode on psychological responses. Psychol Sport Exerc 2004;5:111-117.

100 Pollock ML, Wilmore JH, Fox SM: Health and Fitness through Physical Activity. New York, John Wiley \& Sons, 1978.

101 Shaw K, O’Rourke P, Del Mar C, Kenardy J: Psychological interventions for overweight or obesity. Cochrane Database Syst Rev 2005;2:CD003818.

102 National Institute for Health and Clinical Excellence: Obesity: The Prevention, Identification, Assessment and Management of Overweight and Obesity in Adults and Children. London, NICE, 2006.

103 Jakicic JM, Wing RR, Winters-Hart C: Relationship of physical activity to eating behaviors and weight loss in women. Med Sci Sports Exerc 2002;34:1653-1659. 